\title{
Learning to Love Endoscopy: Lessons from the Five Love Languages About Creating an Optimal Learning Environment for Endoscopic Trainees
}

\author{
Alexander S. Vogel ${ }^{1} \cdot$ Navin L. Kumar ${ }^{1}$ \\ Accepted: 13 July 2021 / Published online: 11 August 2021 \\ (c) The Author(s), under exclusive licence to Springer Science+Business Media, LLC, part of Springer Nature 2021
}

\section{Introduction}

One of the core goals of gastroenterology fellowship programs is to ensure that graduating fellows are competent endoscopists [1]. Most fellowship programs strive to achieve this goal through an apprenticeship model, where fellows (referred herein as trainees) learn directly from paired attending gastroenterologists (trainers). Two challenges of this model are that these relationships vary in length, encompassing everything from a single endoscopic procedure to a multi-month partnership, and trainees vary in experience depending on when the interaction occurs during the course of their training. Though a recent study helped to identify the key competencies of trainers that best facilitated endoscopic teaching, there is limited literature on how trainers can create an optimal clinical learning environment (CLE) for this teaching and learning to occur [2].

\section{Skills Teaching}

A wealth of prior medical education literature has evaluated how to best teach clinical skills. One widely adopted approach is the four-step process originally outlined by Peyton: demonstration (where the trainer performs the skill for the trainee), deconstruction (where the trainer performs the skill while describing what is happening), formulation (where the trainer performs the skill while the trainee describes each step) and finally performance (when the trainee performs the skill while narrating each step) [3]. In this framework, there is an essential interplay between trainee and trainer with careful observation, narration of the steps, and real-time feedback being essential to skill

Alexander S. Vogel

asvogel@bwh.harvard.edu

1 Division of Gastroenterology, Brigham and Women's Hospital, Boston, MA 02115, USA development and mastery. Nevertheless, this framework does not describe how to develop the CLE necessary to enable this learning to occur effectively.

\section{Key Components in Designing an Effective Clinical Learning Environment}

Three crucial concepts in the creation of an ideal CLE are cognitive load, psychological safety and feedback [4-6]. Cognitive load relates to the theory that a person has a limited capacity of working memory at a given time, and by decreasing the number of activities that a person must focus on or think about, more effective learning can occur [4]. Cognitive overload, which occurs when working memory is overwhelmed by the number of simultaneous tasks, is a common and debilitating barrier to skill acquisition for trainees. By decreasing the trainees' cognitive load, trainers can rapidly improve performance [5]. In one study looking at cognitive load in procedural skill training, extraneous cognitive load was reduced when trainers were engaged with the learner throughout the experience, suggesting that trainees can best perform in a trainer-optimized CLE [4]. An important corollary to cognitive load is that of psychological safety, which has been broadly defined as a trainee's perception that the CLE is conducive to taking intrapersonal risk [6]. Actions taken by a trainer to create a CLE that is psychologically safe can thus foster rapid skill development through empowering a trainee to move out of their own comfort zone, without fear of reprimand and with adequate support. The third component of an optimal CLE is the delivery of timely and effective feedback [7]. One useful conception of feedback is that it can be divided between performanceenhancing feedback that often occurs after a procedure in an effort to improve future performance and performanceenhancing training that often occurs during a procedure to help with skill improvement and acquisition in real time [5]. The power of immediate feedback given during a procedure 
is that it furthers error correction in real time in order to prevent incorrect practices from becoming learned and thus repeated [8].

\section{Adapting the Five Love Languages to Endoscopy Teaching}

When thinking about creating a productive CLE for endoscopy teaching, a theory on relationships offers a compelling framework that can be rapidly implemented by trainers. The Five Love Languages, a book by Gary Chapman, outlines five different ways in which people express and experience love [9]. The five love languages are acts of service, words of affirmation, quality time, physical touch, and gifts. What is helpful about this original and now adapted framework is that the different domains, or languages, are geared toward how one person (a trainee) experiences the actions of another person (a trainer) so as to form an optimal relationship. These actions taken by a trainer during endoscopy sessions can quickly establish a safe and effective CLE, encouraging a trainee to thrive and learn. Examples of each language in action are provided in Table 1 and expanded below.

\section{Acts of Service}

During endoscopy sessions, trainees can often feel overwhelmed with the other responsibilities they may have either directly related to endoscopy (i.e., procedural notes, consents) or to other clinical functions they are simultaneously undertaking (i.e., being on call). This can at times lead to cognitive overload, diminishing overall performance and the ability to focus on skill acquisition and improvement during a procedure. Through selectively and proactively helping with these tasks such as completing a procedure note while a trainee responds to urgent pages, a trainer can quickly decrease a trainee's cognitive load and create a more nurturing environment within which a trainee can learn optimally.

\section{Words of Affirmation}

Timely feedback is essential to learning procedural skills. Through commenting, in real time, on specific actions that a trainee takes before, during and after a procedure, a trainee can quickly grow. The added benefit of such feedback is that it signals to the trainee that the trainer is closely paying attention and actively engaged in the procedure, which further leads to a supportive CLE. A key to providing effective feedback is ensuring that a trainee is prepared to receive the feedback, or in other words, has the cognitive load balance such that they can attend to the feedback while still performing the procedure [7].

\section{Quality Time}

Time utilization is a key source of cognitive overload and overall anxiety among trainees during procedures. When a trainer makes it clear that a trainee will have the time and support to participate fully in a procedure, and at times struggle, an enormous weight is lifted. This enables the trainee to learn unencumbered by the fear of having the endoscope prematurely taken away or any degree of resentment from the trainer for delays in a procedure. This does not mean that a trainer must yield the entire procedure to the trainee, but rather that they should be mindful to encourage the trainee to complete as many aspects of the procedure as his or her skill level allows. Examples of this latter approach, which is often particularly required for junior trainees, would be

Table 1 The five love languages adapted to endoscopy training

\begin{tabular}{|c|c|c|}
\hline Love language & Description & Examples of trainer actions \\
\hline Acts of service & $\begin{array}{l}\text { Performing tasks usually done by the fellow when the } \\
\text { trainer senses that the trainee is overwhelmed or behind }\end{array}$ & $\begin{array}{l}\text { Completing the endoscopy note } \\
\text { Consenting the next patient }\end{array}$ \\
\hline Words of affirmation & $\begin{array}{l}\text { Providing targeted feedback in real time, either during or } \\
\text { immediately after the procedure, to highlight effective } \\
\text { actions by the trainee }\end{array}$ & $\begin{array}{l}\text { "That was an excellent reduction after the hepatic flexure" } \\
\text { "Great job getting that polyp to six o'clock" }\end{array}$ \\
\hline Quality time & $\begin{array}{l}\text { Giving a trainee the time necessary to grow as an } \\
\text { endoscopist through maximizing trainee hands-on partici- } \\
\text { pation }\end{array}$ & $\begin{array}{l}\text { Giving the trainee time to work through a difficult pol- } \\
\text { ypectomy } \\
\text { Helping a trainee around a difficult turn but then returning } \\
\text { the endoscope }\end{array}$ \\
\hline Physical touch & $\begin{array}{l}\text { Participating actively during the procedure in ways that } \\
\text { help the trainee to succeed through aiding with patient } \\
\text { positioning and scope handling as needed }\end{array}$ & $\begin{array}{l}\text { Helping to reposition a patient when looping occurs } \\
\text { Helping to advance a device (i.e., snare, forceps) when the } \\
\text { trainee is in a difficult hand position }\end{array}$ \\
\hline Gifts & $\begin{array}{l}\text { When a trainer seeks out and provides the trainee with } \\
\text { valuable endoscopic experiences outside of their normal } \\
\text { session(s) together }\end{array}$ & $\begin{array}{l}\text { Proactively finding an interesting case for the trainee, such } \\
\text { as a dilation, to participate in }\end{array}$ \\
\hline
\end{tabular}


relinquishing the endoscope after helping a trainee around a tight turn, or a trainer withdrawing due to time constraints but permitting the trainee to perform a polypectomy when a polyp is found. Giving a trainee time, and allowing them to actively participate, is perhaps the quickest and most effective way to create a safe CLE.

\section{Physical Touch}

Endoscopy can be a physically grueling activity; assisting with challenging maneuvers can help improve the CLE for the trainee. Whether this takes the form of the trainer adjusting the patient's positioning, assisting with manual pressure, helping to hold the scope while a device is being introduced, or advancing a device when a trainee is in a compromised position, all of these actions help the trainee know that they are being fully supported by the trainer and that the trainer is fully invested in the success of the trainee. By physically aiding a successful trainee, in contrast to taking the endoscope from a trainee at a challenging juncture in a procedure, a trainer not only builds trust but ensures that the trainee feels safe in the learning environment.

\section{Gifts}

As is true in any work relationship with an asymmetric power dynamic, there is often the concern on the part of a trainee of inconveniencing the trainer. One effective way to strengthen the trainer-trainee relationship, and improve a trainee's psychological safety in the relationship, is for the trainer to provide the trainee with experiences that they would not otherwise have. A trainer facilitating experiences for a trainee outside of their normal session sends a clear message to a trainee that the trainer is fully invested in his or her development. Within endoscopy, this can take the form of seeking out the trainee to participate in unusual or challenging procedures in which they would not otherwise be involved, showing the trainee that the trainer is invested in their overall training and development. This support can significantly improve the educational environment for the trainee.

\section{Conclusions}

Our paper proposes a framework, adapted from the five love languages (a popularized framework of how one shows or experiences love), for tangible actions an attending can take to quickly establish an effective learning environment during an endoscopy session. Through acts of service, words of affirmation, quality time, physical touch, and gifts, trainers can maximize the quality of their endoscopic teaching while creating a safe and nurturing space for trainees to learn.

\section{References}

1. American Association for the Study of Liver Diseases, American College of Gastroenterology, American Gastroenterological Association Institute, American Society for Gastrointestinal Endoscopy. The gastroenterology core curriculum, third edition. Gastroenterology. 2007;132:2012-2018.

2. Kumar NL, Smith BN, Lee LS, Sewell JL. Best practices in teaching endoscopy based on a Delphi survey of gastroenterology program directors and experts in endoscopy education. Clin Gastroenterol Hepatol. 2020;18:574-579.e1.

3. Petyon JWR. Teaching and Learning in Medical Practice, Herts: Manticore Europe; 1998; 216.

4. Sewell JL, Boscardin CK, Young JQ, Ten Cate O, O'Sullivan PS. Learner, patient, and supervisor features are associated with different types of cognitive load during procedural skills training: implications for teaching and instructional design. Acad Med. 2017;92:1622-1631.

5. Waschke KA, Anderson J, Macintosh D, Valori RM. Training the gastrointestinal endoscopy trainer. Best Pract Res Clin Gastroenterol. 2016;30:409-419.

6. Caverzagie KJ, Goldenberg MG, Hall JM. Psychology and learning: the role of the clinical learning environment. Med Teach. 2019;41:375-379.

7. Dilly CK, Sewell JL. How to give feedback during endoscopy training. Gastroenterology. 2017;153:632-636.

8. Burgess A, van Diggele C, Roberts C, Mellis C. Tips for teaching procedural skills. BMC Med Educ. 2020;20:458.

9. Chapman GD. The 5 Love Languages: The Secret to Love That Lasts. Chicago: Northfield Publishing; 2015.

Publisher's Note Springer Nature remains neutral with regard to jurisdictional claims in published maps and institutional affiliations. 